\section{Post-Partum Hamman's Syndrome: A Case Report and Literature Review}

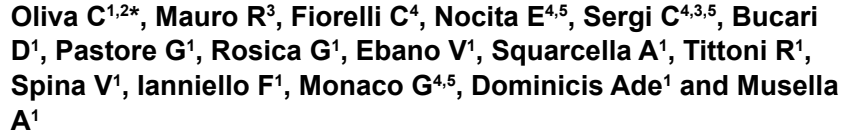

${ }^{1}$ Department of Obstetrics and Gynecology, San Camillo De Lellis Hospital, Rieti, Italy

${ }^{2}$ Unicamillus International Medical University, Rome, Italy

${ }^{3}$ Department of Anesthesiology and Intensive Care, San Filippo Neri Hospital, Rome, Italy

${ }^{4}$ Department of Obstetrics and Gynecology, San Filippo Neri Hospital, Rome, Italy

${ }^{5}$ Department of Obstetrics and Gynecology, "Tor Vergata" University, Rome, Italy

\begin{abstract}
Hereby, the case of a low obstetrical risk nulliparous 25-years-old woman, presenting with chest pain and subcutaneous emphysema on face, neck and sternum four hours after spontaneous vaginal delivery has been reported. Early diagnosis of pneumomediastinum through Computed Tomography (CT) scan, clinical and laboratory exams allowed a timely and adequate management without further complications. Differential diagnosis with Hamman's syndrome has to be taken in mind in case of cough, chest pain, breath difficulty arising after labour and vaginal delivery.
\end{abstract}

Keywords: Chest pain; Delivery; Pneumomediastinum; Subcutaneous emphysema

\section{Introduction}

Post-partum spontaneous pneumomediastinum, known as Hamman's syndrome, was firstly described in 1945 by Louis Hamman [1]. It is defined by a, non-injury-cause, free air presence in the

${ }^{*}$ Corresponding author: Oliva C, Department of Obstetrics and Gynecology, San Camillo De Lellis Hospital, 02100, Rieti, Italy, Tel: +39 0746278270; E-mail: c.oliva@asl.rieti.it

Citation: Oliva C, Mauro R, Fiorelli C, Nocita E, Sergi C, et al. (2021) Post-Partum Hamman's Syndrome: A Case Report and Literature Review. J Reprod Med Gynecol Obstet 6: 089.

Received: December 04, 2021; Accepted: December 10, 2021; Published: December 17, 2021

Copyright: (c) 2021 Oliva C, et al. This is an open-access article distributed under the terms of the Creative Commons Attribution License, which permits unrestricted use, distribution, and reproduction in any medium, provided the original author and source are credited. mediastinum and represents a rare complication of second stage of labour with an incidence rate of 1 in 100.000 deliveries [2-11]. Globally, its incidence is approximately $1 / 25.000$ between 5 and 34 years old and the majority of patients $(70 \%)$ are males [12]. It has been most commonly reported in young nulliparous women. Despite worrying symptoms, the course of this disease is self-limiting [2]. It is usually clinically evident only in the postpartum period even if it occurs from the second stage of labour [10]. Chest pain is the most common symptom of pneumomediastinum, although the severity depends on the location and amount of air. Additional symptoms may include dyspnea, cough and palpitations. Subcutaneous emphysema in the neck has also been linked to vomiting during pregnancy [4]. Excessive Valsalva manoeuvre during vaginal delivery and excessive retching, coughing and straining are frequently reported causes. Pathophysiology of this condition is alveoli's fissure and infiltration of air through broncho-vascular connective tissue. Eventually subcutaneous emphysema is the result of diffusion of air to subcutaneous tissues [8]. Chest X-ray is a useful early diagnostic technique. We report the case of a twentyfive-year-old woman who was diagnosed with Hamman's syndrome after her vaginal delivery.

\section{Case Report}

A 25-years-old Caucasian woman, nulliparous with unremarkable obstetrical history was admitted to the Department of Obstetrics and Gynecology of San Filippo Neri Hospital at her 41 weeks of gestation because of labour beginning. She was smoker, also during pregnancy, and presented a Body Mass Index (BMI) of 26,7. Her medical history included involvement in a car accident two years before pregnancy resulting in a whiplash injury that was treated with a cervical collar neck for about 2 months. The first stage of labour was uneventful and, as requested from the woman, an epidural catheter for the labour analgesia was placed after anesthesiological evaluation and informed consent signed, without any complications. To encourage the contractions and stabilize them a continuous infusion of oxytocin, with an initial dose of $5 \mathrm{UL}$ in $500 \mathrm{ml}$ of physiological solution at $0,9 \%$ at a speed of $3 \mathrm{ml} / \mathrm{h}$ was started (according to the protocol of our hospital the speed of the infusion gets doubled every 30 minutes). The woman experienced a single episode of sickness in the early hours of the labour. After about five hours from admission the uterine cervical dilation progresses to $4 \mathrm{~cm}$, with subsequent spontaneous amniotic sac rupture and release of clear liquid. Consequently, the continuum infusion of Oxycitin was suspended (up to a $60 \mathrm{ml} / \mathrm{h}$ ) due to the start of regular and intense contractions. After one hour, a complete cervical dilation was detected. During the second stage of the labour continuous cardiotocographic monitoring was performed and the Foetal Heart Rate (FHR) was always regular. After approximately 2 hours of active pushing, delivery of her baby happened successfully and neither episiotomy nor the Kristeller's manoeuvre were necessary. The baby was in good general health conditions with a body weight of $4,340 \mathrm{~kg}$ and an Apgar score of 9 at 5 mins after birth.

At $10 \mathrm{pm}$, four hours after deliver, the woman presented a serious subcutaneous emphysema on her face, neck, collarbones and sternum. A CT scan was immediately performed with detection of pneumomediastinum and no signs of pneumothorax or any other issues on the pulmonary parenchyma were found (Figure 1). The radiological 
Citation: Oliva C, Mauro R, Fiorelli C, Nocita E, Sergi C, et al. (2021) Post-Partum Hamman’s Syndrome: A Case Report and Literature Review. J Reprod Med Gynecol Obstet 6: 089.

report showed "an abundant presence of a subcutaneous emphysema, with pneumomediastinum. There was an anterolateral irregularity in the wall of trachea, above the carina" (Figure 2). The patient felt a little pain on her chest but hemodynamic and respiratory parameters were always regular. The physical examination was normal except for the presence of a subcutaneous emphysema from her jaw to her sternum. The emergency surgeon and the pneumologist were also consulted and the patient was transferred to the referral pneumological center at Agostino Gemelli Hospital in Rome.

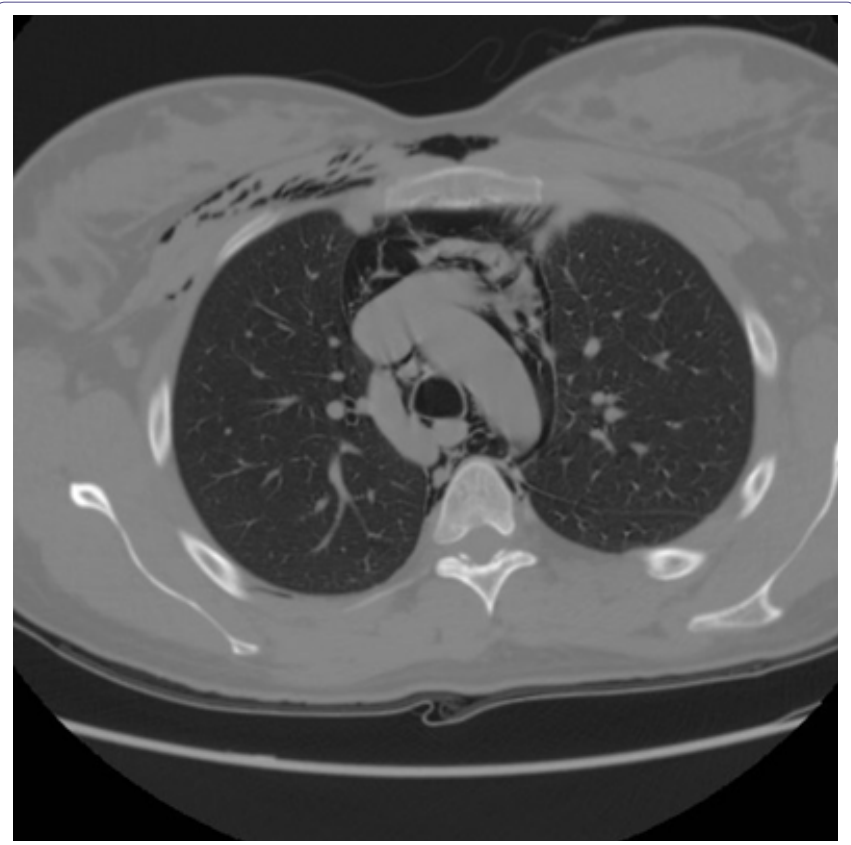

Figure 1: Thoracic computed tomography showing pneumomediastinum and abundant subcutaneous emphysema.

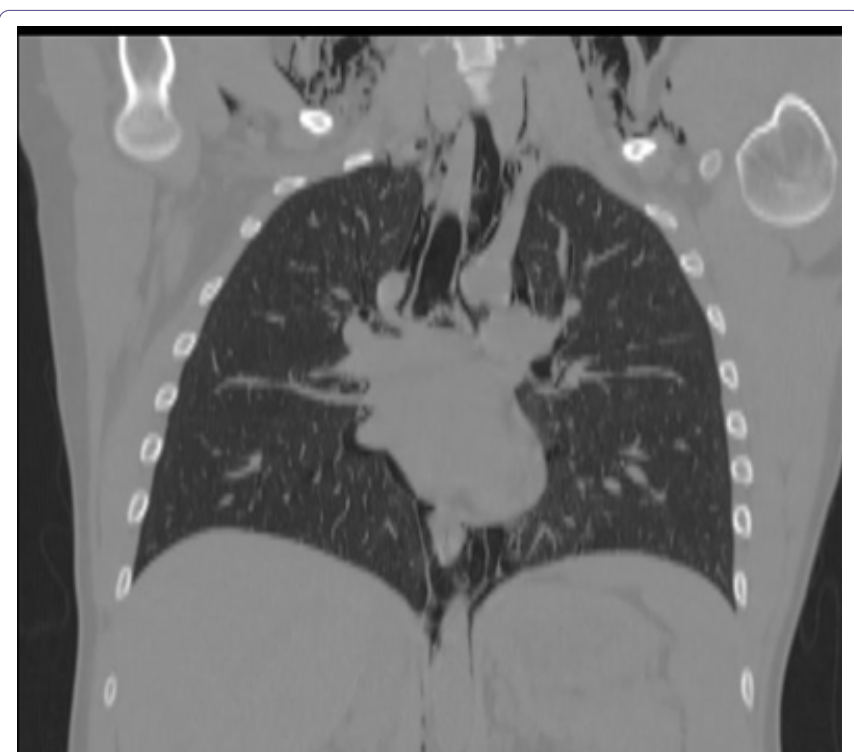

Figure 2: Chest computed tomography showing pneumomediastinum and subcutaneous emphysema and an anterolateral irregularity in the wall of trachea.

There, the patient was checked for further 24 hours, repeated chest X-ray (Figure 3) and CT scan with no evidence of tracheal rupture but confirming the presence of pneumomediastinum with subcutaneous emphysema. No alterations of Arterial Blood Gas (ABG) analysis were detected. The thoracic surgery team kept the patient under observation, treated her conservatively with analgesia and antibiotics and disposed a next a chest X-ray after seven days of treatment. Subsequently the woman returned to our Hospital, she received multiple pneumological controls and chest $\mathrm{CT}$ scan and X-ray were performed once again, revealing pneumomediastinum decrease and subcutaneous emphysema reduction. Eight days after spontaneous delivery, she was discharged home in good general health conditions without other post-partum complications and with scheduled chest $\mathrm{X}$-ray after one month. At one year of follow-up she is healthy and asymptomatic.

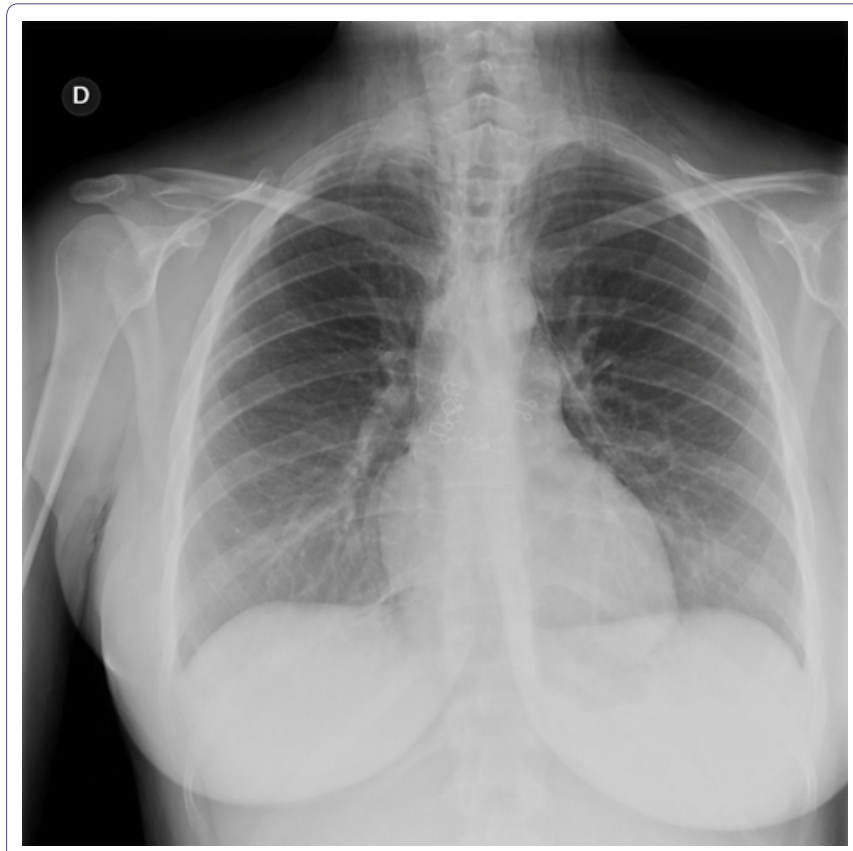

Figure 3: Chest X-rays showing pneumomediastinum and subcutaneous emphysema.

\section{Discussion}

Pneumomediastinum associated with pneumothorax and subcutaneous emphysema is a rare obstetric complication. The causal mechanism of Hamman's syndrome is thought to be due to excessive intrathoracic pressure associated with Valsalva manoeuvre which leads to distal alveolar rupture [13]. Valsava' s manoeuvre, is a forced expiratory effort against a closed or blocked air passage. Inevitably, it is employed during labour when coughing, vomiting, screaming or pushing and rarely, it causes a break-up of the alveoli and the income of air into the mediastinum [5]. Few cases of pregnancy-related Hamman's have been reported in literature until now [2-9,14-22], with chest pain as most common symptom ( $85 \%$ of patients), followed by crepitus $(71 \%)$ [23]. Other symptoms include facial or neck swelling, dyspnea, tachycardia and dysphonia [24,25]. Hamman' syndrome treatment is symptomatic. Chest pain, dyspnoea, anxiety can be treated with oxygen, analgesics and sedatives [5]. Prognosis is generally favourable and the course is self-limited; nevertheless, a prompt diagnosis is basic for an adequate management [2]. Chest X-ray is considered the primary investigation method, however chest CT remains the gold standard for detecting pneumomediastinum [26]. Because of its rarity, no standard management of Hamman's syndrome or prevention in future pregnancies is still available. Fortunately most of 
Citation: Oliva C, Mauro R, Fiorelli C, Nocita E, Sergi C, et al. (2021) Post-Partum Hamman’s Syndrome: A Case Report and Literature Review. J Reprod Med Gynecol Obstet 6: 089.

- Page 3 of $3 \cdot$

cases are uncomplicated and conservative treatment remains the most appropriate [23]. The differential diagnosis of a Hamman's syndrome includes amniotic fluid embolism, pulmonary embolism, myocardial infarction, pneumothorax, aortic dissection, Boerhavee's syndrome, interstitial emphysema, pneumopericardium, cardiac tamponade and mediastinitis [7]. After this experience, considering timing of labour and vaginal delivery, we can assume that nulliparity, a prolonged second stage of labour associated with pushing could be risk factors for pneumomediastinum. This case led us to consider Hamman' syndrome as differential diagnosis when symptoms as cough, chest pain and difficult breath are reported by the patients during a prolonged second stage of labour or after delivery. Our purpose is to highlight this occurrence in order to raise awareness health professionals of pregnancy-related Hamman's syndrome and make early diagnosis and timely appropriate management.

\section{References}

1. Hamman L (1945) Mediastinal emphysema: The frank billings lecture. Journal of the American Medical Association 128: 1-6.

2. Kouki S, Fares AA (2013) Postpartum spontaneous pneumomediastinum ‘Hamman’s syndrome'. BMJ Case Rep 2013: bcr2013010354.

3. Dilley JWR (2011) Postpartum hearing loss: An unusual presentation of Hamman's syndrome. J Obstet Gynaecol 31: 268-269.

4. Tixier H, Rattin C, Dunand A, Peaupardin Y, Douvier S, et al. (2010) Hamman's syndrome associated with pharyngeal rupture occurring during childbirth. Acta Obstet Gynecol Scand 89: 407-408.

5. Zapardiel I, Delafuente-Valero J, Diaz-Miguel V, Godoy-Tundidor V, Bajo-Arenas JM (2009) Pneumomediastinum during the fourth stage of labor. Gynecol Obstet Invest 67: 70-72.

6. Mahboob A, Eckford SD (2008) Hamman's syndrome: An atypical cause of postpartum chest pain. J Obstet Gynaecol 28: 652-653.

7. Yadav Y, Ramesh L, Davies JA, Nawaz H, Wheeler R (2008) Gross spontaneous pneumomediastinum (Hamman's syndrome) in a labouring patient. J Obstet Gynaeco 28: 651-652.

8. Majer S, Graber P (2007) Postpartum pneumomediastinum (Hamman's syndrome). CMAJ 177: 32.

9. Bonin MM (2006) Hamman's syndrome (spontaneous pneumomediastinum) in a parturient: A case report. J Obstet Gynaecol Can 28: 128-131.

10. Raley JC, Andrews JI (2001) Spontaneous pneumomediastinum presenting as jaw pain during labor. Obstet Gynecol 98: 904-906.

11. Krause H, Portmann C (2000) Pneumomediastinum following vaginal delivery. Aust NZJ Obstet Gynaecol 40: 106-107.
12. Grapatsasa K, Tsilogianni Z, Leivaditis V, Kotoulas S, Kotoulas C, et al. (2018) Hamman's syndrome (spontaneous pneumomediastinum presenting as subcutaneous emphysema): A rare case of the emergency department and review of the literature. Respir Med Case Rep 23: 63-65.

13. Seidl JJ, Brotzman GL (1994) Pneumomediastinum and subcutaneous emphysema following vaginal delivery. Case report and review of the literature. J Fam Pract 39: 178-180.

14. Dhaliwal HS (2019) Spontaneous pneumomediastinum (Hamman's syndrome) following a vaginal delivery. The New Indian Journal of OBGYN 6: 67-70.

15. Woolford TJ, Birzgalis AR, Lundell C, Farrington WT (1993) Vomiting in pregnancy resulting in oesophageal perforation in a 15-year-old. J Laryngol Otol 107: 1059-1060.

16. Revicky V, Simpson P, Fraser D (2010) Postpartum pneumomediastinum: an uncommon cause for chest pain. Obstet Gynecol Int 2010: 956142.

17. Wijesuriya J, Van Hoogstraten R (2015) Postpartum Hamman's syndrome presenting with facial asymmetry. BMJ Case Rep 2015: bcr2015213397.

18. Elshirif A, Tyagi-Bhatia J (2016) Postpartum pneumomediastinum and subcutaneous emphysema (Hamman's syndrome). J Obstet Gynaecol; 36: 281-282.

19. Cho C, Parratt JR, Smith S, Patel R (2015) Spontaneous pneumomediastinum (Hamman's syndrome): A rare cause of postpartum chest pain. BMJ Case Rep 2015: bcr1220103603.

20. Khurram D, Patel B, Farra MW (2015) Hamman's Syndrome: A Rare Cause of Chest Pain in a Postpartum Patient. Case Rep Pulmonol 2015: 201051.

21. Kandiah S, Iswariah H, Elgey S (2013) Postpartum pneumomediastinum and subcutaneous emphysema: Two case reports. Case Rep Obstet Gynecol 2013: 1-3.

22. Kuruba N, Hla TT (2011) Postpartum spontaneous pneumomediastinum and subcutaneous emphysema: Hamman's syndrome. Obstet Med 4: 127128.

23. Macia I, Moya J, Ramos R, Morera R, Escobar I, et al. (2007) Spontaneous pneumomediastinum: 41 cases. Eur J Cardiothorac Surg 31: 1110-1114.

24. James RE, Bhanu C, Hapuarachi S, Leyva Caraballo E (2019) Facial swelling and dysphonia during labour: A case of Hamman's syndrome. BMJ Case Rep 12: 227489.

25. Oshovskyy V, Poliakova Y (2020) A rare case of spontaneous pneumothorax, pneumomediastinum and subcutaneous emphysema in the II stage of labour. Int J Surg Case Rep 70: 130-132.

26. Kaneki T, Kubo K, Kawashima A, Koizumi T, Sekiguchi M, et al. (2000) Spontaneous pneumomediastinum in 33 patients: Yield of chest computed tomography for the diagnosis of the mild type. Respiration 67: 408-411. 


\section{H}

Advances In Industrial Biotechnology | ISSN: 2639-5665

Advances In Microbiology Research | ISSN: 2689-694X

Archives Of Surgery And Surgical Education | ISSN: 2689-3126

Archives Of Urology

Archives Of Zoological Studies | ISSN: 2640-7779

Current Trends Medical And Biological Engineering

International Journal Of Case Reports And Therapeutic Studies | ISSN: 2689-310X

Journal Of Addiction \& Addictive Disorders | ISSN: 2578-7276

Journal Of Agronomy \& Agricultural Science | ISSN: 2689-8292

Journal Of AIDS Clinical Research \& STDs | ISSN: 2572-7370

Journal Of Alcoholism Drug Abuse \& Substance Dependence | ISSN: 2572-9594

Journal Of Allergy Disorders \& Therapy | ISSN: 2470-749X

Journal Of Alternative Complementary \& Integrative Medicine | ISSN: 2470-7562

Journal Of Alzheimers \& Neurodegenerative Diseases | ISSN: 2572-9608

Journal Of Anesthesia \& Clinical Care | ISSN: 2378-8879

Journal Of Angiology \& Vascular Surgery | ISSN: 2572-7397

Journal Of Animal Research \& Veterinary Science | ISSN: 2639-375

Journal Of Aquaculture \& Fisheries | ISSN: 2576-5523

Journal Of Atmospheric \& Earth Sciences | ISSN: 2689-8780

Journal Of Biotech Research \& Biochemistry

Journal Of Brain \& Neuroscience Research

Journal Of Cancer Biology \& Treatment | ISSN: 2470-7546

Journal Of Cardiology Study \& Research | ISSN: 2640-768X

Journal Of Cell Biology \& Cell Metabolism | ISSN: 2381-1943

Journal Of Clinical Dermatology \& Therapy | ISSN: 2378-8771

Journal Of Clinical Immunology \& Immunotherapy | ISSN: 2378-8844

Journal Of Clinical Studies \& Medical Case Reports | ISSN: 2378-880

Journal Of Community Medicine \& Public Health Care | ISSN: 2381-1978

Journal Of Cytology \& Tissue Biology | ISSN: 2378-9107

Journal Of Dairy Research \& Technology | ISSN: 2688-9315

Journal Of Dentistry Oral Health \& Cosmesis | ISSN: 2473-6783

Journal Of Diabetes \& Metabolic Disorders | ISSN: 2381-201X

Journal Of Emergency Medicine Trauma \& Surgical Care | ISSN: 2378-8798

Journal Of Environmental Science Current Research | ISSN: 2643-5020

Journal Of Food Science \& Nutrition | ISSN: 2470-1076

Journal Of Forensic Legal \& Investigative Sciences | ISSN: 2473-733X

Journal Of Gastroenterology \& Hepatology Research | ISSN: 2574-2566
Journal Of Genetics \& Genomic Sciences | ISSN: 2574-2485

Journal Of Gerontology \& Geriatric Medicine | ISSN: 2381-8662

Journal Of Hematology Blood Transfusion \& Disorders | ISSN: 2572-2999

Journal Of Hospice \& Palliative Medical Care

Journal Of Human Endocrinology | ISSN: 2572-9640

Journal Of Infectious \& Non Infectious Diseases | ISSN: 2381-8654

Journal Of Internal Medicine \& Primary Healthcare | ISSN: 2574-2493

Journal Of Light \& Laser Current Trends

Journal Of Medicine Study \& Research | ISSN: 2639-5657

Journal Of Modern Chemical Sciences

Journal Of Nanotechnology Nanomedicine \& Nanobiotechnology | ISSN: 2381-2044

Journal Of Neonatology \& Clinical Pediatrics | ISSN: 2378-878X

Journal Of Nephrology \& Renal Therapy | ISSN: 2473-7313

Journal Of Non Invasive Vascular Investigation | ISSN: 2572-7400

Journal Of Nuclear Medicine Radiology \& Radiation Therapy | ISSN: 2572-7419

Journal Of Obesity \& Weight Loss | ISSN: 2473-7372

Journal Of Ophthalmology \& Clinical Research | ISSN: 2378-8887

Journal Of Orthopedic Research \& Physiotherapy | ISSN: 2381-2052

Journal Of Otolaryngology Head \& Neck Surgery | ISSN: 2573-010X

Journal Of Pathology Clinical \& Medical Research

Journal Of Pharmacology Pharmaceutics \& Pharmacovigilance | ISSN: 2639-5649

Journal Of Physical Medicine Rehabilitation \& Disabilities | ISSN: 2381-8670

Journal Of Plant Science Current Research | ISSN: 2639-3743

Journal Of Practical \& Professional Nursing | ISSN: 2639-568

Journal Of Protein Research \& Bioinformatics

Journal Of Psychiatry Depression \& Anxiety | ISSN: 2573-0150

Journal Of Pulmonary Medicine \& Respiratory Research | ISSN: 2573-0177

Journal Of Reproductive Medicine Gynaecology \& Obstetrics | ISSN: 2574-2574

Journal Of Stem Cells Research Development \& Therapy | ISSN: 2381-2060

Journal Of Surgery Current Trends \& Innovations | ISSN: 2578-7284

Journal Of Toxicology Current Research | ISSN: 2639-3735

Journal Of Translational Science And Research

Journal Of Vaccines Research \& Vaccination | ISSN: 2573-0193

Journal Of Virology \& Antivirals

Sports Medicine And Injury Care Journal | ISSN: 2689-8829

Trends In Anatomy \& Physiology | ISSN: 2640-7752

Submit Your Manuscript: https://www.heraldopenaccess.us/submit-manuscript 